\title{
Symmetric acral annular erythema: a variant of erythema annulare centrifugum, necrolytic acral erythema or a distinct clinical entity?
}

\author{
Radomir Reszke', Zdzisław Woźniak², Adam Reich ${ }^{3}$ \\ ${ }^{1}$ Department of Dermatology, Venereology and Allergology, Wroclaw Medical University, Wroclaw, Poland \\ ${ }^{2}$ Department of Pathomorphology, Wroclaw Medical University, Wroclaw, Poland \\ ${ }^{3}$ Department of Dermatology, University of Rzeszow, Rzeszow, Poland
}

Adv Dermatol Allergol 2019; XXXVI (2): 234-236

DOI: https://doi.org/10.5114/ada.2019.84599

Erythemas occur due to the dilation of blood vessels, especially those in the papillary and reticular dermis, clinically resulting in the change of the skin colour [1]. This group of dermatoses is very heterogenous, encompassing figurate erythemas such as erythema annulare centrifugum (EAC) or necrolytic erythemas, including necrolytic acral erythema (NAE). Due to the abundance of morphological variants and eliciting factors, the classification and diagnosis of erythematous lesions may be challenging, especially in patients suffering from other diseases or taking many pharmaceuticals.

A 62-year-old woman was admitted to our department due to skin lesions that had appeared approximately 8 months earlier. The patient was suffering from compensated liver cirrhosis associated with chronic hepatitis C virus ( $\mathrm{HCV}$ ) infection (previously treated with pegylated interferon $\alpha$ and ribavirin), hypertension and thrombocytopenia. The lesions had been regarded as a manifestation of vasculitis and treated with topical ( $0.05 \%$ clobetasol propionate), oral (methylprednisolone up to $32 \mathrm{mg} /$ day) and intravenous (methylprednisolone 500 mg pulse therapy) corticosteroids (CS) without any significant clinical improvement. On admission, the patient was receiving methylprednisolone (32 mg/day), perindopril ( $5 \mathrm{mg}$ / day), bisoprolol ( $5 \mathrm{mg} /$ day), pantoprazole (20 mg/day), furosemide (20 mg/day), and nitrendipine (10 mg/day). Upon clinical examination, symmetrical erythematous lesions with scattered sterile pustules, prominent inflammatory border and a slight haemorrhagic component were observed on dorsal aspects of the feet (Figures $1 \mathrm{~A}$, B). A moderate palpable oedema was visible on the dorsal surface of the feet and lower $1 / 3$ of shins. The patient complained of burning sensation of the feet. Laboratory examinations revealed low platelet count $\left(35,000 / \mathrm{mm}^{3}\right)$, elevated serum liver enzymes (AST $68 \mathrm{U} /$, ALT $95 \mathrm{U} /$,
GGTP $82 \mathrm{U} / \mathrm{l}$ ) and IgG cryoglobulinemia. A skin biopsy was performed from the inflammatory border of a lesion located on the medial malleolus. Histological examination revealed marked lymphohistiocytic "coat sleeve" infiltrates around dilated superficial and deep blood vessels with scarce eosinophils, oedema of papillary dermis, hyperkeratosis and focal epidermal spongiosis (Figure $1 \mathrm{~F}$ ). The clinical morphology and histological pattern supported the diagnosis of EAC, whereas the concurrent HCV infection, location and symmetric distribution of lesions suggested the diagnosis of NAE.

We initiated tacrolimus $0.1 \%$ ointment twice daily and oral zinc supplementation (100 mg/day), while the dose of methylprednisolone was reduced to $16 \mathrm{mg} /$ day. After 6 weeks of therapy the lesions subsided almost completely (Figures 1 D, E). Burning sensation disappeared as well. Topical tacrolimus therapy and oral zinc supplementation were sustained, along with further methylprednisolone dose reduction (8 $\mathrm{mg} /$ day).

In general, EAC begins with erythematous or urticarial-type papules, gradually spreading and forming larger annular, arcuate or polycyclic rings with central clearing [2]. Characteristic desquamation on the inner margin is often visible in the superficial EAC type, whereas nonscaly infiltrated plaques in the deep type. The most common locations include the lower extremities, trunk, upper extremities, head and neck. The EAC is thought to represent a hypersensitivity reaction associated with infections, malignancies, drugs or stress [3-6], to name just a few. Histological examination usually reveals dense perivascular lymphocyte infiltration in the upper dermis (so called "coat-sleeve appearance"), occasionally with epidermal changes [2].

In a patient with a concurrent HCV infection, lesions located acrally on the dorsal aspects of the feet strongly

Address for correspondence: Prof. Adam Reich MD, PhD, Department of Dermatology, University of Rzeszów, 2 Szopena St, 35-055 Rzeszow, Poland, phone: +48 605076 722, fax: +48 1786662 94, e-mail: adi_medicalis@o2.pl Received: 3.11.2017, accepted: 30.11.2017. 

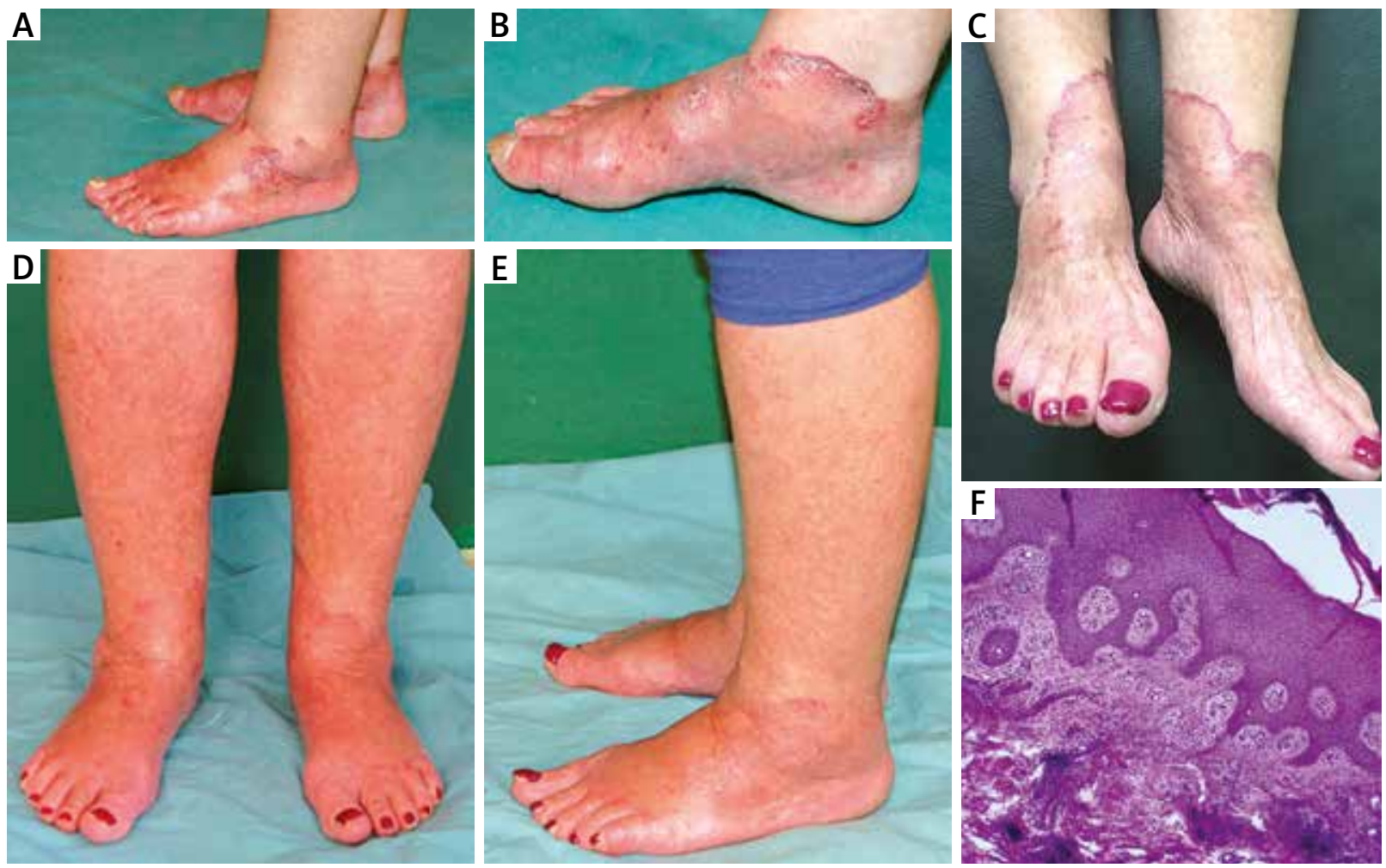

Figure 1. A - Erythematous lesions with sterile pustules on the dorsal surface of the feet. B - A close-up of lesions located on the medial ankle with a marked inflammatory border. C - Cutaneous lesions during treatment with topical tacrolimus. Almost complete clearance of cutaneous lesions after 6 weeks of treatment on the dorsal surface of the feet (D) and on the lateral ankle (E). F - Histological evaluation of the erythemas revealing hyperkeratosis and focal epidermal spongiosis, oedema of papillary dermis, lymphohistiocytic "coat sleeve" infiltrates around dilated superficial and deep blood vessels (H\&E stain, 100× magnification)

implicate the diagnosis of NAE. However, despite the term "erythema", the fully-developed lesions mainly present as violaceous psoriasiform plaques, whereas erythema is not the major clinical finding. Pruritus may accompany the lesions. Histology reveals acanthosis, hyperkeratosis, inflammatory infiltrate in upper dermis and clustering of necrotic keratinocytes [7]. The pathogenesis of NAE is not fully understood, although HLA-DRB1 alleles, C3 and C4 proteins of component and low serum zinc levels are suspected [8].

In our case, despite presenting certain common features of well-described entities, we believe that the clinical presentation is distinct enough to suspect another, yet not described, skin disease. We propose the term "symmetric acral annular erythema" (SAAE) which seems to adequately reflect the clinical manifestation of the disease. Although clinical and histological similarities to EAC are present, exclusive acral and symmetric distribution of lesions is not typical for EAC. There are only a few case descriptions in the literature which share some similarities with our patient. A case-series study on EAC $(n=39)$ mentioned one patient with lesions located on both ankles and five patients with both legs affected [9]. A case of EAC located symmetrically on lower extremities and hands which was induced by concurrent interferon- $\alpha 2 a$ and ribavirin therapy due to HCV infection was also published [5]. The lesions occurred approximately 3-4 days after instigating the therapy and regressed shortly after discontinuing antiviral drugs. Interferon and ribavirin had also been administered in our patient in the past, but the skin lesions appeared several years after cessation of such therapy. Distal distribution of lesions and concurrent HCV infection might suggest the diagnosis of NAE. However, the skin lesions lacked psoriasiform morphology and histological examination neither revealed features of psoriasis nor necrolysis (Table 1).

The treatment that we instigated in our patient was based on papers reporting its usefulness in NAE [10-12]. Other investigators reported the efficacy of combined interferon and ribavirin treatment [13] or topical CS [7]. However, our patient had been previously treated with topical clobetasol propionate and systemic methylprednisolone without any clinical improvement, while topical tacrolimus and oral zinc supplementation provided significant response. It must be noted that tacrolimus was evaluated in one paper on NAE [12]. In addition, two cases of idiopathic EAC resistant to CS therapy with further resolution of symptoms due to topical tacrolimus were also 
Table 1. Aetiological, clinical, histological and therapeutic aspects associated with EAC, NAE and the present case

\begin{tabular}{|c|c|c|c|}
\hline $\begin{array}{l}\text { Typical aspects } \\
\text { associated with } \\
\text { the diseases enlisted } \\
\text { on the right }\end{array}$ & EAC & NAE & Present case (SAAE) \\
\hline Aetiology & $\begin{array}{l}\text { Multifactorial (infections, malignant } \\
\text { neoplasms, drug intake, bullous } \\
\text { disorders, SLE, food, pregnancy, stress) }\end{array}$ & HCV infection & $\begin{array}{l}\text { Possible association with HCV } \\
\text { infection }\end{array}$ \\
\hline Clinical features & $\begin{array}{l}\text { Erythematous plaques with annular } \\
\text { configuration and central clearing. } \\
\text { Scales present in the superficial type, } \\
\text { whereas deep type manifests with a firm, } \\
\text { indurated border }\end{array}$ & $\begin{array}{l}\text { Erythematous and } \\
\text { hyperpigmented plaques } \\
\text { with scales and erosion, } \\
\text { particularly on the dorsal } \\
\text { surface of the feet }\end{array}$ & $\begin{array}{l}\text { Erythematous lesions on both feet, } \\
\text { with scattered sterile pustules and } \\
\text { a marked inflammatory border }\end{array}$ \\
\hline Histological features & $\begin{array}{l}\text { Superficial type: perivascular lymphocytic } \\
\text { infiltration in the upper dermis ("coat- } \\
\text { sleeve appearance"), occasionally } \\
\text { spongiosis, hyperkeratosis, parakeratosis. } \\
\text { Deep type: perivascular lymphocytic } \\
\text { infiltration in superficial and deep dermis }\end{array}$ & $\begin{array}{l}\text { Acanthosis, hyperkeratosis, } \\
\text { infiltration in upper dermis. } \\
\text { Necrotic keratinocytes } \\
\text { (characteristic, but not } \\
\text { present in every case) }\end{array}$ & $\begin{array}{l}\text { Hyperkeratosis and focal epidermal } \\
\text { spongiosis, oedema of papillary } \\
\text { dermis, marked lymphohistiocytic } \\
\text { "coat sleeve" infiltrates around } \\
\text { dilated superficial and deep blood } \\
\text { vessels, scarce eosinophils }\end{array}$ \\
\hline Treatment regimens & $\begin{array}{l}\text { CS (topical, systemic) } \\
\text { Tacrolimus topically } \\
\text { Calcipotriol topically } \\
\text { Metronidazole } \\
\text { Etanercept (subcutaneously) } \\
\text { Interferon } \alpha \text { (subcutaneously) }\end{array}$ & $\begin{array}{l}\text { Oral zinc } \\
\text { Oral amino acids } \\
\text { CS topically } \\
\text { Interferon alfa } \\
\text { subcutaneously } \\
\text { Ribavirin } \\
\text { Tacrolimus topically }\end{array}$ & $\begin{array}{l}\text { Oral zinc } \\
\text { Tacrolimus topically }\end{array}$ \\
\hline
\end{tabular}

described [14]. Zinc dosage in the treatment of NAE varied among reports, ranging from $60 \mathrm{mg} /$ day to $440 \mathrm{mg} /$ day $[10,11]$.

In conclusion, we suggest that SAAE might be a new clinical entity sharing features of both EAC and NAE, with a potential beneficial therapeutic effect of topical tacrolimus and oral zinc supplementation. Further investigations regarding this issue will be of utmost value.

\section{Acknowledgments}

The study was conducted in: Department of Dermatology, Venereology and Allergology, Wroclaw Medical University, Wroclaw, Poland.

\section{Conflict of interest}

The authors declare no conflict of interest.

\section{References}

1. Espana A. Erythemas. In: Dermatology. $3^{\text {rd }}$ edn. Bolognia JL, Jorizzo J, Schaffer JV (eds.). Elsevier Saunders, London 2012; 307-17.

2. Kim KJ, Chang SE, Choi JH, et al. Clinicopathologic analysis of 66 cases of erythema annulare centrifugum. J Dermatol 2002; 29: 61-7.

3. Lee HW, Lee DK, Rhee DY, et al. Erythema annulare centrifugum following herpes zoster infection: Wolf's isotopic response? Br J Dermatol 2005; 153: 1241-3.
4. Chodkiewicz HM, Cohen PR. Paraneoplastic erythema annulare centrifugum eruption: PEACE. Am J Clin Dermatol 2012; 13: 239-46.

5. Gönül M, Külcü Çakmak S, Ozcan N, et al. Erythema annulare centrifugum due to pegylated interferon-alpha-2a plus ribavirin combination therapy in a patient with chronic hepatitis C virus infection. J Cutan Med Surg 2014; 18: 65-8.

6. Ibrahim SF, Pryor J, Tausk FA. Stress-induced erythema annulare centrifugum. Dermatol Online J 2009; 15: 15.

7. Abdallah MA, Ghozzi MY, Monib HA, et al. Necrolytic acral erythema: a cutaneous sign of hepatitis C virus infection. J Am Acad Dermatol 2005; 53: 247-51.

8. Moneib HA, Salem SA, Darwish MM. Evaluation of zinc level in skin of patients with necrolytic acral erythema. Br J Dermatol 2010; 163: 476-80.

9. Kim DH, Lee JH, Lee JY, et al. Erythema annulare centrifugum: analysis of associated diseases and clinical outcomes according to histopathologic classification. Ann Dermatol 2016; 28: 257-9.

10. el Darouti M, Abu el Ela M. Necrolytic acral erythema: a cutaneous marker of viral hepatitis C. Int I Dermatol 1996; 35: 252-6.

11. Abdallah MA, Hull C, Horn TD. Necrolytic acral erythema: a patient from the United States successfully treated with oral zinc. Arch Dermatol 2005; 141: 85-7.

12. Manzur A, Siddiqui AH. Necrolytic acral erythema: successful treatment with topical tacrolimus ointment. Int I Dermatol 2008; 47: 1073-5.

13. Hivnor CM, Yan AC, Junkins-Hopkins JM, et al. Necrolytic acral erythema: response to combination therapy with interferon and ribavirin. J Am Acad Dermatol 2004; 50: S121-4.

14. Rao NG, Pariser RJ. Annular erythema responding to tacrolimus ointment. J Drugs Dermatol 2003; 2: 421-4. 